\title{
Review of: "Effect of Copper Donor Material Assisted Friction Stir Welding of AA6061-T6 Alloy On Downward Force, Microstructure, And Mechanical Properties"
}

\author{
dianlong wang ${ }^{1}$ \\ 1 Hebei University of Science and Technology
}

Potential competing interests: The author(s) declared that no potential competing interests exist.

1. It is better to set up a control group without the aid of copper donor material.

2. The content of donor material assisted friction stir welding should be added in the literature review section.

3. Please describe the contents of diagrams a-d in Figure 2.

4. It is better to add more analysis of experimental results to highlight your understanding of the subject.

5. Ref[42-43]should not appear before [41]. 